\title{
SEDATION FOR OPHTHALMIC SURGERY* COMBINATION OF CHLORPROMAZINE, PROMEZATHINE, AND PETHIDINE
}

\author{
BY \\ R. A. BURN, D. A. B. HOPKIN, G. EDWARDS, AND C. M. JONES
}

From the Royal Eye Unit, Lambeth Hospital, London

DESPITE regional blocks, retro-bulbar injections, and pre-operative barbiturate sedation, intra-ocular surgery can still be a hazardous procedure. Apprehension and the accompanying general increase in muscle tone which enhance the risks of such operations as intra-capsular cataract extraction are only partially overcome by these methods. General anaesthesia, with its tendency to venous congestion in the head and vomiting on recovery, offers no solution. Any method of sedation which will induce mental and physical relaxation in a tense and apprehensive patient, without the disadvantages of general anaesthesia, would be of great value.

Experience with chlorpromazine ("Largactil"), promezathine ("Phenergan "), and pethidine in premedication for general anaesthesia suggested that a combination of these drugs might fulfil the requirements of ocular surgery. Patients who were given the mixture showed, at the time of induction, an absence of apprehension and a degree of mental and physical relaxation not found with barbiturate sedation, and their post-operative recovery was remarkably free from restlessness and untroubled by the nausea, vomiting, and respiratory depression which tends to accompany sedation with opiates. On theoretical grounds also such a combination seemed likely to be of value. Burn (1954) compared the common properties of a large number of substances, including chlorpromazine, promezathine and pethidine, and mentioned in particular a reduction of the excitability of skeletal muscle and prolongation of the sleep produced by pentobarbitone. Decourt (1953) described a number of properties of chlorpromazine, including central depressant and hypnotic effects, potentiation of analgesics and local anaesthetics, and anti-emesis; Anton-Stephens (1954) emphasized, in psychiatric patients under the influence of the drug, an attitude of indifference to their surroundings and a loss of the anxiety and distress which arise from feelings of tension. It seemed that these effects of chlorpromazine ("Largactil "), combined with and potentiating the analgesic properties of pethidine and the hypnotic effect of promezathine ("Phenergan") and already known to be effective in premedication for general anaesthesia, might induce favourable conditions for ophthalmic surgery.

This combination of drugs has been tried as a form of sedation for ocular surgery under local anaesthesia, and the operative conditions produced

-Received for publication March 14, 1955. 
have been compared with those obtained by the standard methods of barbiturate sedation.

\section{Material and Dosage}

Material.-Operations under local anaesthesia using this method of sedation were performed on 89 patients. The operations are shown in Table I.

TABLE I

TYPES OF OPERATION PERFORMED

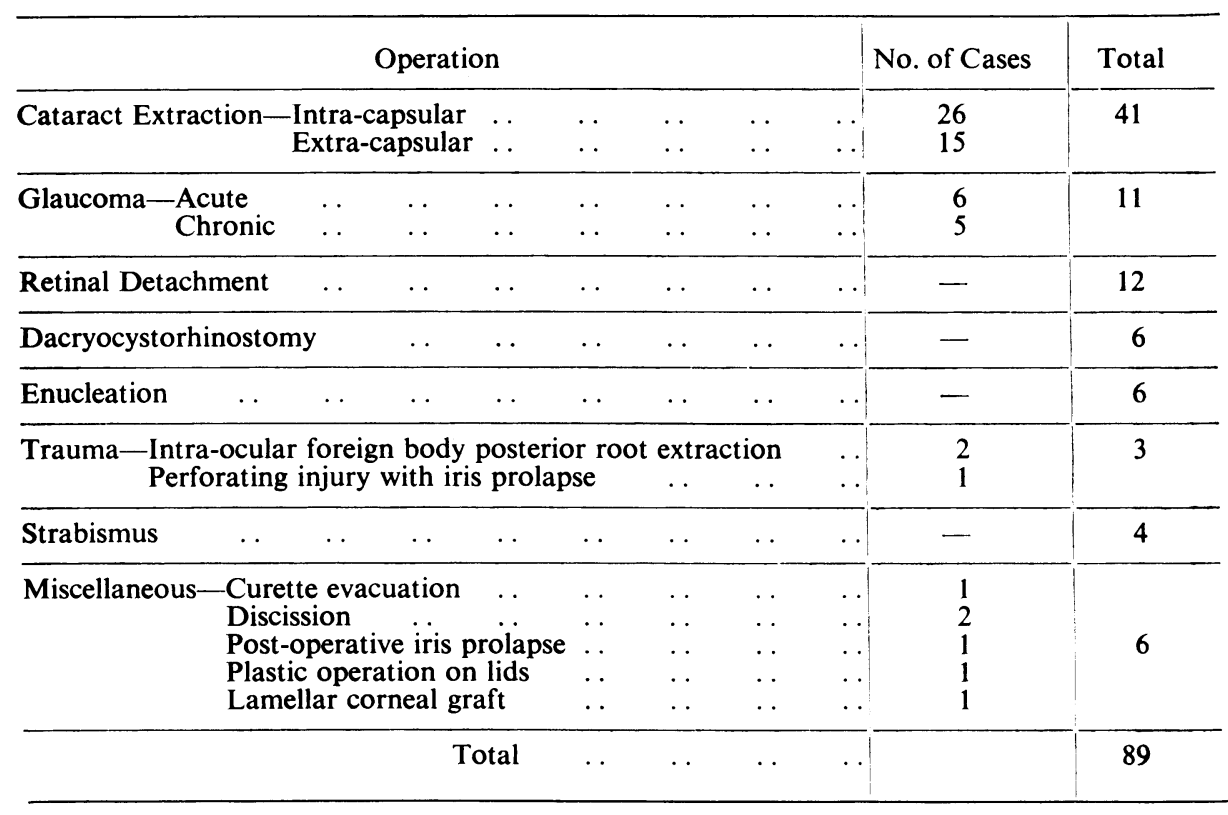

Cataract extraction accounts for almost half the total but they cover the normal range of routine ophthalmic surgery including emergency, traumatic, plastic, and lacrimal operations.

The ages of the patients varied from 23 to 91 years; their distribution by

TABLE II

DISTRIBUTION OF PATIENTS BY AGE

\begin{tabular}{c|c}
\hline Age (Yrs) & No. of Cases \\
\hline $20-29$ & 9 \\
$30-39$ & 4 \\
$40-49$ & 10 \\
$50-59$ & 14 \\
$60-69$ & 18 \\
$70-79$ & 27 \\
$80-89$ & 6 \\
$90-99$ & 1 \\
\hline Total & 89 \\
\hline
\end{tabular}
age groups is shown in Table II. Particular attention was paid to the following points at operation:

\section{Mental relaxation;}

Muscular relaxation ;

Spontaneous movements of eyes or limbs;

Response to painful stimuli such as the upper-lid injection, superior rectus stitch, or iridectomy ;

Amount of haemorrhage ;

Response to orders and questions. 
In 28 cases serial blood pressure and pulse readings were taken, and in six cases the intra-ocular pressure was measured in the unoperated eye before and after giving the drugs. The conditions at operation were evaluated and compared with those found in similar cases under standard barbiturate sedation. For the purpose of this comparison the type of barbiturate sedation envisaged was that in standard use in the department, namely luminal gr. 3 given $1 \frac{1}{2} \mathrm{hrs}$ pre-operatively.

During the post-operative period particular attention was paid to the following points :

Nausea, retching and vomiting ;

Restlessness and disorientation ;

Duration of sedation ;

Retention of urine ;

General post-operative complications such as pneumonia and thromboses ;

Ocular complications such as hyphaema and iris prolapse.

The patient's comments, spontaneous and elicited, were also recorded in a number of cases.

Dosage.-The great majority of cases were given chlorpromazine (" Largactil ") $50 \mathrm{mg}$., promezathine ("Phenergan ") $50 \mathrm{mg}$., and pethidine $100 \mathrm{mg}$. by the intravenous route. In a very few cases a rather smaller dose in the same proportions was given, and in sixteen cases the intramuscular route was used. This dosage had already been used satisfactorily as premedication for general anaesthesia in a large number of cases. No other form of sedation was used. When using the intravenous technique the drugs were given 20-30 minutes before the operation. The dose of all three substances was diluted in $20 \mathrm{ml}$. saline and injected very slowly. As the importance of slow administration became evident a minimum period of 10 minutes was adopted for the injection. In this way the progress of pulse and blood pressure could be watched and administration stopped if the full dose seemed likely to have too great an effect. When using the intramuscular route the full dose was given 1-2 hrs before the operation.

In all cases local anaesthesia was used exactly as with luminal sedation. For intra-ocular operations, surface anaesthesia with 4 per cent. cocaine drops was combined with a facial nerve block, lid stitch injections, and a retrobulbar injection of $1.5 \mathrm{ml}$. using 5 per cent. procaine or 2 per cent. xylocaine with adrenaline 1:40,000. For other operations local infiltrations according to standard procedures were used. Two operations for squint in adults were done under surface cocaine only.

\section{Anaesthetic Aspects}

The appearance of patients under the influence of these drugs is characteristic. They lie quietly and appear to be asleep. According to the depth of sedation they may answer questions and obey orders easily, or they may snore and be apparently unrousable, though they always show some response to painful stimuli. There is a marked pallor of the face and bloodlessness of the lips which may be alarming unless it is expected, and the skin is noticeably cold to the touch. 
Serial blood pressure readings were made in 28 cases, starting before the administration of the drugs and continuing for some time after the patient had returned to the ward. A fall of both systolic and diastolic pressures is the rule, and it is responsible in part for the good operative conditions obtained. It is much more marked with intravenous than with intramuscular administration. The greatest fall in systolic pressure noted was one of $135 \mathrm{~mm} . \mathrm{Hg}$, from 240 to $105 \mathrm{~mm}$. $\mathrm{Hg}$; the greatest fall in diastolic pressure was one of $70 \mathrm{~mm}$. $\mathrm{Hg}$, from 110 to $40 \mathrm{~mm}$. $\mathrm{Hg}$. The average fall in systolic pressure was $55 \mathrm{~mm}$. $\mathrm{Hg}$ and in diastolic pressure $32 \mathrm{~mm}$. $\mathrm{Hg}$. The fall reaches a maximum shortly after administration is complete, and the pressure begins to rise again in a few minutes, returning gradually to pre-operative levels in 6 to $8 \mathrm{hrs}$.

When the intravenous route is used there is a tendency to severe temporary tachycardia unless the injection is given very slowly. It lasts no longer than 10 to 15 minutes as a rule and no case of collapse has occurred, but it may be alarming to both the patient and the anaesthetist. In order to reduce both the tachycardia and the fall in blood pressure the injection should be given evenly and slowly over a period of 10 to $15 \mathrm{~min}$. With this technique no difficulties have been encountered. When the intramuscular route is used, both tachycardia and hypotension are minimal. The fall in blood pressure has been well tolerated, but it was thought best to keep the patients lying flat until it began to rise again.

The method is entirely safe in the hands of an anaesthetist with experience of these drugs. None of the present series of cases gave cause for anxiety, and the method has been used by one of us (D.A.B.H.) in over 500 cases as premedication for general anaesthesia with no unfavourable reactions. The toxic effects of chlorpromazine have been reported mainly in cases undergoing prolonged courses of the drug for psychiatric purposes, and no case of a dangerous reaction to a single dose given for anaesthetic purposes is known to us. Nevertheless known liver disease and severe diabetes have been considered to be a contraindication to its use so far.

\section{Surgical Aspects}

In all cases, except in two operations for squint, the conditions obtained at operation were superior to those provided by luminal sedation. In a number of cases almost ideal conditions were encountered where great difficulty would have been expected, and in at least one case it is doubtful whether the operation could have been successfully performed in any other way. Conditions in the immediate post-operative period were on the whole better than those obtained with luminal and had none of the disadvantages associated with general anaesthesia. The drugs were not used routinely for post-operative sedation so that the later recovery period was little different from that following any other type of sedation. 
Conditions at Operation.-The patients appeared to be asleep although they could often answer questions and obey simple instructions. They were completely relaxed mentally and physically and there were no signs of anxiety or apprehension. Even in the most nervous cases there was a complete absence of "squeezing" when drops were put in the eye or the lids were handled before the facial block had been given. On the other hand the patients were not anaesthetized and protested against painful stimuli either vocally or by moving. Such sudden movements, although sometimes quite marked and less controlled than under luminal sedation, subsided immediately the stimulus was withdrawn and were not followed by the prolonged " guarding" and rigidity so troublesome in apprehensive patients under luminal. The surgical procedures which most often gave rise to them were the lid injections, pulling on the extra-ocular muscles, and, rarely, the insertion of a superior rectus stitch. In emergency surgery and when operating on congested eyes a few such protests occurred, but in general they were much rarer and less troublesome than those encountered in patients under luminal sedation. They are emphasized because, when they do occur, they are apt to come as a surprise in a patient who appears to be unconscious.

In the intra-ocular operations the absence of anxiety and apprehension combined with generalized muscular relaxation, including that of the extraocular muscles, was the outstanding feature. Gaping of the wound, vitreous presentation or loss, and prolapse of the iris were not encountered in any case. There was no tendency for the eyes to turn up and no resistance to passive movement in any direction. The intra-ocular pressure, in the cases in which it was measured, showed either no change, or, more often, a fall of up to $10 \mathrm{~mm}$. Hg. Taken digitally it was usually low but never sufficiently reduced to make section cutting difficult. Bleeding, in all cases, was recorded as minimal. Both the fall in intra-ocular pressure and the absence of haemorrhage were probably produced by the fall in arterial blood pressure and the absence of venous congestion in the head consequent upon easy respiration and muscular relaxation. Most patients protested mildly against the lid injections and a very few during the insertion of the superior rectus stitch. These procedures appear to be the most painful steps in most intra-ocular operations and nothing else evoked any significant response. In particular, only one patient showed any sign of feeling pain from an iridectomy and this was a mild and harmless protest during an operation on a severely congested eye. In no case of cataract extraction did any troublesome movement occur in response to pain after the section was made. One old lady, who was confused and subject to sudden purposeless movements before operation, moved her head several times quite independently of any sensory stimulus, but these movements were without effect on her general state of muscular relaxation; there was no tendency to vitreous prolapse, and an intra-capsular extraction was completed through a round 
pupil without complications. In general, the conditions obtained for intraocular operations were excellent, the most significant features being the muscular relaxation and the absence of any tendency to vitreous presentation or prolapse even in the few cases in which some spontaneous movement occurred.

In extra-ocular surgery the muscular relaxation and freedom from apprehension and anxiety combined with a definite reduction in haemorrhage to produce better conditions for most operations than those provided by standard barbiturate sedation or general anaesthesia. This was perhaps best shown in the case of enucleations. Apart from an occasional mild protest at pulling on the extra-ocular muscles the patients tolerated the operation well. The absence of fear and anxiety allowed local anaesthesia to be used in all types of patient and the relative absence of haemorrhage made the operation simpler and the post-operative recovery shorter than with general anaesthetics. In dacryocystorhinostomy the intramuscular route was preferred in case too deep sedation should lead to inhalation of blood. When combined with slight raising of the head and the infiltration of local anaesthetics containing adrenaline, the method provided excellent conditions for the operation, haemorrhage was minimal, and in no case did inhalation of fluid occur. For retinal detachment surgery also the conditions were superior to those provided by luminal sedation. In squint surgery, however, the protests resulting from pulling on the extra-ocular muscles were a source of trouble. One operation had to be completed under pentothal for this reason and in one other some difficulty was experienced. The other two operations for squint were completed under good conditions, one of them with cocaine drops only.

Post-Operative Recovery.-The immediate post-operative recovery of these cases was very satisfactory and distinctly better than after luminal. If undisturbed they slept peacefully until the morning after operation although they could be roused enough to answer questions. Additional sedatives were rarely needed on the night of operation. It is difficult to assess the duration of sedation, since the patients emerge very gradually from the influence of the drugs, but it was estimated to be 6-10 hrs in most cases. These drugs were not used routinely for post-operative sedation, so that once this stage was passed the conditions were much the same as those found after standard methods of pre-operative sedation.

In ten cases some nausea, retching, or vomiting was recorded, but in none of them was it severe or harmful. In only two of these cases did retching or vomiting occur in the immediate post-operative period. No more cases had this complication than would have been likely to have it under luminal sedation and very many fewer than after general anaesthesia.

Some degree of restlessness was recorded in the immediate post-operative period in eight cases. In all but one it was very slight and in none did it lead to any ocular complications. It is more difficult to enlist the voluntary 
co-operation of the patient with this method than after luminal sedation, and they do not always lie rigidly in one position. This disadvantage is compensated by the patient's complete relaxation and peaceful sleep.

General complications were few and could not be attributed to the method of sedation. The only ones of importance were three cases of bronchopneumonia of which two recovered uneventfully and one, a woman of 78 who developed the condition a week after operation, died. There were no cases of thrombosis in any area. Several patients did not pass urine for 20-24 hrs after operation but had no subsequent difficulty. This could be attributed to the prolonged post-operative sleep and low fluid intake.

The commonest ocular post-operative complication was hyphaema. This occurred in twelve out of 41 cases of cataract extraction. Of these only three developed within the first $\mathbf{4 8}$ hours, the remainder, including all the important ones, occurring at the usual time between the third and sixth days. Since the method as used did not cover this critical period it could not affect the incidence of this complication. In addition to the cases of hyphaema there was one case of iris prolapse, which occurred on the 6th day after operation, and one of delayed reformation of the anterior chamber with choroidal detachment. The incidence of post-operative ocular complications was approximately what might have been expected in a similar series after using standard methods of barbiturate sedation.

Most patients remembered little or nothing of the operation and were quite satisfied with the method. Two patients had two similar operations each, one with luminal and one with this type of sedation; both of them preferred this method. Dry mouth was a common complaint, but this could be relieved by giving sips of water without danger of causing vomiting. One patient only said he felt pain during the operation but was unable to protest; nevertheless the operative conditions in his case were excellent from the surgical point of view. Several patients remembered much of what had been said and done in the operating theatre although they had given the impression of being deeply anaesthetized.

\section{Case Reports}

The following reports illustrate cases in which good conditions were obtained at operation although considerable difficulty would have been expected using standard methods of sedation.

(1) A woman, aged 77, was admitted with acute congestive glaucoma of the left eye, the right eye being blind from previous acute glaucoma. She was a fragile old woman with marked cardiac irregularity, confused, apprehensive, very difficult to examine, and considered unfit for a general anaesthetic.

She was given chlorpromazine $50 \mathrm{mg}$., Phenergan $50 \mathrm{mg}$., and pethidine $100 \mathrm{mg}$. intramuscularly $1 \frac{1}{2} \mathrm{hrs}$ before the operation. A broad iridectomy was done by the $a b$ externo method under excellent conditions, with minimal extra-ocular haemorrhage and no hyphaema. There was no spontaneous movement during the operation, and complete relaxation. Recovery was uninterrupted and the visual acuity achieved was 6/12 with correction. 
It is doubtful whether this operation could have been performed successfully in any other way.

(2) A man, aged 53, with long-standing inflammatory glaucoma, was very apprehensive and intolerant of pain, with little self-control. He was given chlorpromazine $50 \mathrm{mg}$., Phenergan $50 \mathrm{mg}$., and pethidine $100 \mathrm{mg}$. intramuscularly $1 \frac{1}{2} \mathrm{hrs}$ before the operation. A broad iridectomy was done under good conditions with minimal protest against upper-lid injection and superior rectus stitch only. Recovery was uninterrupted, apart from some retching on returning to the ward.

This operation would have been very difficult if not impossible under local anaesthesia with luminal sedation.

(3) A man," aged 26, with bilateral chronic simple glaucoma, was a very intelligent patient with good self-control, but apprehensive. He was given chlorpromazine $50 \mathrm{mg}$., Phenergan $50 \mathrm{mg}$., and pethidine $100 \mathrm{mg}$. intravenously 15 minutes before the operation. A cyclodialysis was done under very good conditions, with a mild protest against face towel only, which subsided immediately this was adjusted. During an identical operation on the other eye under luminal sedation this patient was much more tense and a hyphaema occurred at operation. He expressed a preference for "Largactil" sedation.

(4) A woman, aged 63, was admitted with bilateral acute congestive glaucoma, she was vomiting and shocked, apprehensive, and in very severe pain.

She was given chlorpromazine $25 \mathrm{mg}$., Phenergan $25 \mathrm{mg}$., and pethidine $100 \mathrm{mg}$. intravenously 15 minutes before the operation. Despite the half dose a bilateral broad iridectomy was done under excellent conditions, with no spontaneous movement during the operation, and complete relaxation. Recovery was uninterrupted, apart from a small post-operative hyphaema in one eye, which absorbed.

This bilateral operation would have been difficult under local anaesthesia with luminal sedation.

\section{Discussion}

The advantages of this technique are unquestionable, especially in cataract surgery, and, by comparison, luminal sedation appears inadequate except for minor procedures. Absence of apprehension and tenseness, with muscular relaxation but without the disadvantages of general anaesthesia are the outstanding features, and reduction of haemorrhage is a useful secondary effect. It should be possible to reduce most of the disadvantages, such as tachycardia and excessive hypotension, to a minimum by varying the method of administration, the dose, and possibly some of the drugs employed. The tendency to spontaneous movement in response to painful stimuli, however, appears to be a limitation inherent in the method which confines its use to procedures in which pain can be effectively controlled by local anaesthesia. The experimental work of Hiebel, Bonvallet, and Dell (1954) on chlorpromazine is of interest in this connexion. They showed that the effect of chlorpromazine on the electrocorticogram of the cat is to eliminate all rapid activity and produce slow, irregular, waves similar to those seen in sleep. A sensory stimulus causes a burst of rapid activity similar to that produced in the normal animal, but lasting no longer than the stimulus itself, whereas, in the normal animal it would continue long 
after the stimulus was withdrawn. The behaviour of patients under this type of sedation agrees with these experimental findings. They appear to be anaesthetized and are completely relaxed, but once a stimulus exceeds the pain threshold it will give rise to a response which, because of the absence of self-control, may be more violent than under barbiturate sedation, but which will subside completely once the stimulus is withdrawn. This liability to sudden, uncontrolled movements is less troublesome than might be expected, and has never outweighed the advantages of the method except in operations for squint. With good local anaesthesia the pain threshold is rarely passed, and the procedures which tend to exceed it, such as the upper-lid injection or the insertion of a superior rectus stitch, are not carried out during the most critical stages of an operation. Moreover, when such reactions do occur, they are short-lived and local, and do not involve the intense, prolonged, generalized increase in muscle tone which is so dangerous in apprehensive patients under luminal sedation.

With these advantages and limitations, the relative value of the method in the various types of operation follows the lines that would be expected. In the surgery of cataract, retinal detachment, and chronic glaucoma, the conditions at operation have been excellent. In cases of acute glaucoma and in emergency operations on young, apprehensive men, spontaneous movement has occasionally occurred, but in most cases it could probably have been avoided by adjustment of the dose. In extra-ocular operations, especially enucleation and dacryocystorhinostomy, the conditions at operation are very good and the hypotensive effect is of value in reducing haemorrhage. In squint surgery, however, the uncontrolled movements which may be caused by pulling on the extra-ocular muscles are a serious disadvantage. It does not seem possible, in some cases, to control the pain from this procedure with local anaesthetics, and since some degree of tenseness and rigidity is not a bar to the operation it is probably better, if local anaesthesia is to be used, to leave the patient's self-control unimpaired and to operate under luminal sedation, or none.

It is probable that the dosage necessary to produce a satisfactory depth of sedation varies according to the type of operation, the age, weight and, personality of the patient; so that a standard method such as has been employed in this series so far cannot give the best results. Considerable improvement should be obtained by varying the dosage, the method of administration, and the drugs employed. In a recent report, Dejean and Jaulmes (1954) describe the use in ophthalmic surgery under local anaesthesia of a large number of substances, including those used in this series. The method can be extended to include pre-operative and post-operative sedation adapted to individual patients and operative procedures, and it seems likely that developments on these lines will supersede the present standard method of barbiturate sedation. 


\section{Conclusion}

The conditions provided at operation by this method for almost all forms of ophthalmic surgery under local anaesthesia are much better than those provided by luminal sedation, without the disadvantages of general anaesthesia. Muscular relaxation and complete absence of apprehension or tenseness combined with minimal bleeding are the outstanding features. It is important to remember that the patients are not anaesthetized and that their self-control is impaired, so that if the pain threshold is passed uncontrolled movements may result. In practice this limitation has not proved serious except in operations of squint.

The immediate post-operative recovery of these patients is at least as good as after luminal sedation and is free from the risks involved in recovery from general anaesthesia.

\section{Summary}

The use of a combination of chlorpromazine, promezathine, and pethidine by intravenous or intramuscular injection as a form of sedation for ophthalmic surgery under local anaesthesia is described in a series of 89 cases. The conditions produced at operation, and during post-operative recovery, are compared with those obtained by standard methods of barbiturate sedation such as luminal. The method was found to give better conditions at operation than luminal in almost all types of ophthalmic surgery except squint. Immediate post-operative recovery was at least as good as after luminal and free from the disadvantages of recovery from general anaesthesia.

Our acknowledgements are due to Prof. A. Sorsby and Mr. T. M. Tyrrell for permission to use the details of some of their cases at whose operations one of us assisted, to Dr. J. E. Bulow and Dr. G. Hurter who gave the drugs to a number of the patients, and to Sisters Thorogood, Altenberger, and Condon of the Royal Eye Unit, Lambeth Hospital, for their help in nursing and observing these patients.

\section{REFERENCES}

ANTON-STEPHENS, D. (1954). J. ment. Sci., 100, 543.

BuRn, J. H. (1954). Proc. roy. Soc. Med., 47, 617.

Decourt, P. (1953). Thérapie, 8, 846.

DeJean, C., and JaUlmes, M. (1954). Arch. Ophtal., 14, 679.

Hinbel, G., Bonvallet, M., and Dell, P. (1954). Sem. Hôp., Paris, 30, 2346. 